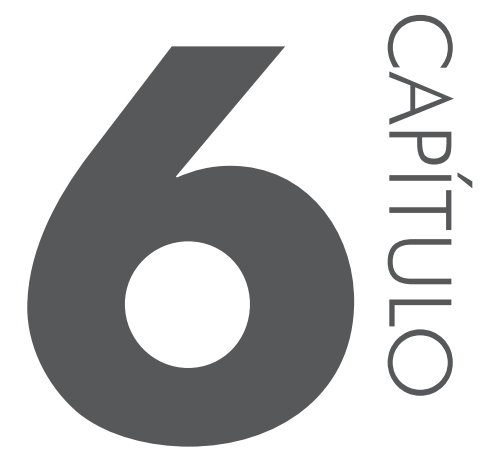

\title{
História e meio-ambiente no Planalto sul de Angola (1850-1890)
}

\section{José Nilo Bezerra Diniz}

Universidade Federal de Santa Catarina

\section{Introdução}

O mapeamento cartográfico da hinterlândia da África meridional foi tardio, mas uma vez iniciado, foi extremamente célere e rigoroso. No cenário internacional, a descoberta do diamante no Transvaal (1867), do ouro na região do Rand (1881) e das reservas de cobre na Rodésia produziu novas expectativas de exploração rentável do continente. A inserção da bacia do rio Congo na política diplomática europeia após a Conferência de Bruxelas (1876), e as disputas interimperiais que então se desdobraram, acirraram ainda mais a conjuntura denominada de "partilha da África" (BRUNSCHWIG, 2013, p. 19-20).

A investigação do mundo natural por meio de levantamentos botânicos, zoológicos, etnográficos, geográficos, dentre outros, foi de grande importância para o posterior domínio colonial da África, e muitas das expedições organizadas deixaram entrever as disputas das potências imperiais por territórios. Em particular, o estudo da hidrografia acentuou ainda mais esse quadro. Focamos dois exemplos coetâneos: a expedição de Savorgnan de Brazza (1875-1878), que tinha por fito navegar o rio Ogowe até a sua nascente, a fim de encontrar um acesso que facultasse aos franceses as matérias primas do alto Congo; e a viagem de costa a costa 
de Henry Stanley (1874-1877), na qual ele navegou no escaler Lady Alice até a foz do rio Zaire. ${ }^{1}$ Após o reconhecimento da bacia hidrográfica do Congo, de seus tributários e das suas possibilidades de exploração, ambos os expedicionários iniciaram uma disputa de legitimação de posse da região, tendo como subterfúgio a assinatura de tratados - muitas vezes contestáveis - com os chefes locais. Além da França e da Bélgica, Portugal também reclamava os direitos sobre o baixo Congo (Zaire), apoiando-se na alegação de que detinha "direitos históricos" sobre a região. ${ }^{2}$ Esta querela só cessaria em 1885, com a criação do Estado Livre do Congo na Conferência de Berlim, organizada para tratar do livre comércio desse rio e também do de toda a África Central. ${ }^{3}$ Essa conferência acabaria por estabelecer novos parâmetros para a posse de um território, ao exigir, por exemplo, sua ocupação efetiva, bem como a criação de postos de civilização no local e o combate à escravidão. ${ }^{4}$ No âmbito da política externa, as outras potências acusavam a administração portuguesa de displicência e até diziam-na compassiva a escravidão. Mormente a Inglaterra, principal nação a levantar a bandeira abolicionista. Nesse aspecto, ficaram espetacularmente conhecidas as denúncias perpetradas pelo missionário David Livingstone (LIVINGSTONE, 1865, 1859). Além disso, as potências europeias questionavam as capacidades lusitanas de arcar com os custos necessários para civilizar suas colônias (ALEXANDRE, 2004, p. 974).

$\mathrm{Na}$ África, o real domínio português era incipiente e por vezes descontínuo, pois dependia de uma delicada negociação com os régulos e os chefes locais. O território era assentado em uma rede de caminhos de terra, assessorada por

1 Sobre a viagem de Brazza, conferir: (BRAZZA, 1992; BORY, 1890, p. 223). Já a viagem de Stanley, realizada sob os auspícios dos jornais Daily Telegraph e New York Herald, consistiu na exploração da bacia do Zaire por meio da navegação realizada em um barco desmontável em cinco sessões, o que possibilitava o seu desmanche em trechos não navegáveis, como rápidos e quedas. (Cf. STANLEY, 2007, p. 35-39).

2 A ideia de que Portugal detinha direitos históricos sobre a África Central se ancorava nas descobertas marítimas do século XV e em algumas investidas ao íntimo do continente nos séculos subsequentes. No entanto, como afirma Valentim Alexandre, esse argumento ganhou mais densidade e maior difusão entre as diversas camadas da população no último quartel do século XIX, com a emergência de um nacionalismo radical e marcadamente imperialista. (Cf. ALEXANDRE, 2004, p. 972-973).

3 Brazza assinou em 1880 o famoso tratado Brazza-Makoko, que estendia proteção francesa às regiões de Makoko e seus vassalos. Em 1882, Stanley utilizou-se da mesma estratégia de firmar acordos e passou a conceder proteção em nome de Leopoldo II, então rei da Bélgica. Para a questão da disputa do Congo, vide: (WESSELING, 1998, p. 83-147; WESSELING, 2009, p. 368-372).

4 Entenda-se por ocupação efetiva a inserção compulsória dos estados e reinos africanos à lógica capitalista exportadora, em conjunto com a exploração dos recursos naturais desses lugares. 
alguns presídios dispersos que conectavam os sertões do interior aos centros litorâneos, muitos deles formados pela parceria luso-africana em torno do infame comércio de escravos. A manutenção da rede de comércio de longa distância era constantemente ameaçada, quer pela presença de comerciantes estrangeiros, quer pelo descompasso entre o interesse do Estado português e o de seus súditos.

\section{Viagens científicas de exploração à África}

Foi nessa arena de disputa pelo território da África centro-meridional que a Sociedade de Geografia de Lisboa (SGL), em 1875, foi fundada. Desde sua criação, foi patente o interesse da SGL em atuar na produção de conhecimento acerca da porção centro-austral do continente africano, região onde se concentrava as duas principais possessões portuguesas, Angola e Moçambique. A forte aliança entre essa sociedade científica lisboeta e a colonização da África pode ser percebida na fundação de uma pasta interna específica para discutir questões relacionadas a isso, já em 27 de março de 1877. Tratava-se da Comissão Nacional Portuguesa de Exploração e Civilização da África, simplesmente conhecida como Comissão Africana (GUIMARÃES, 1984, p. 34; BSGL, 1878, p. 218-219). Essa comissão tinha como escopo discutir e fomentar projetos colonizadores que assegurassem o desenvolvimento das possessões portuguesas no continente africano, bem como discutir, no âmbito internacional, a legitimidade lusa sobre essas regiões.

Nesse sentido, a criação de expedições científicas de exploração tinha um papel central, pois elas serviriam para produzir um saber segundo os cânones da ciência, com validade também nos campos político e diplomático. Por isso, em 16 de outubro de 1876, mesmo antes da criação da Comissão Africana, o presidente da sociedade, Visconde de S. Januário, junto com os secretários Luciano Cordeiro e Rodrigo Pequito, exortaram o rei, D. Luís I, sobre a importância de amealhar recursos em diferentes âmbitos, para se realizar uma expedição científica integralmente portuguesa. Segundo os autores, a nação portuguesa, que, há séculos, descobriu e percorreu os sertões africanos, não poderia ficar indiferente ao crescente interesse de sociedades geográficas da Inglaterra, da Alemanha, da França e da Itália em perscrutar a hinterlândia da África (BSGL, 1877, p. 19-23).

Em outro apelo, agora elaborado pela Comissão Central Permanente de Geografia, Luciano Cordeiro e seus pares se queixavam de que o conhecimento prático dos portugueses era sistematicamente desconsiderado pelo conjunto de exploradores modernos, embora fosse "difícil dizer qual o lago, rio ou outro lugar assinalados pelos descobridores modernos nas vastas bacias dos rios africanos, o Nilo, o Zaire e o Zambeze, de que não existam indícios mais ou menos certos indicados primeiros pelos viajantes ou colonos portugueses" (BSGL, 1877, p. 23-27). 
O mesmo diagnóstico fora dado anos antes pelo experiente sertanejo Silva Porto, ao encontrar-se com o explorador e missionário inglês, David Livingstone, na corte do Barotze, em 1853. Em um pequeno opúsculo dirigido ao combate daquilo que o sertanejo considerou injusto ou difamatório na obra de Livingstone a seu respeito, Porto afirma que "outro tanto não direi da situação geográfica dos lugares aqui indicados, atendendo a que não são marcados com a bussola, mas sim segundo a posição em que nasce e se põe o sol" (PORTO, 1891, p. 8). Sem dúvida, Silva Porto percebeu o enorme fosso que separava os seus mais de quinze anos de tirocínio, percorrendo e negociando por todo o sertão da África centro-austral os equipamentos geodésicos, mapas, cartas e outros instrumentos, com os quais o britânico seguia munido.

Urgia, pois, que os próprios portugueses se lançassem também na corrida exploratória. Assim, a partir de 1877, a Sociedade de Geografia de Lisboa iria não só levantar capital humano, técnico e financeiro para a concretização dessas explorações, mas também funcionaria como uma "central de cálculo", para usar uma conceituação de Bruno Latour. ${ }^{5}$ Interessam à discussão aqui travada as duas grandes expedições encabeçadas pela SGL que percorreram parte da porção meridional de Angola, sobretudo as terras do Alto Cunene e as terras entre os rios Cubango e Cuando. A primeira delas foi chefiada por dois oficiais da marinha, Hermenegildo Capelo e Roberto Ivens, e pelo oficial do exército Alexandre de Serpa Pinto. Seus trabalhos tiveram início em 1877, na cidade de Benguela, de onde seguiram juntos até o Bié para então cindirem-se em duas expedições: Serpa Pinto seguiu o curso do oriente até chegar no Oceano Índico, em Durban, cidade da colônia britânica do Cabo, em 1879; Capelo e Ivens se mantiveram fieis às orientações acordadas na sessões da SGL e aprovadas pela Comissão Central Permanente de Geografia, percorrendo a hinterlândia da África Central sem tentarem a travessia. A segunda expedição, que teve início em 1884, contou apenas com os mesmos dois oficiais da marinha e chegou ao fim um ano depois, após uma travessia continental.

Ao mesmo tempo que a hinterlândia passou a ser cortada em todas as dire-

5 Para Bruno Latour (2000, p. 396), “construir centros implica trazer para eles elementos distantes - permitir que os centros dominem a distância -, mas sem trazê-los "de verdade" - para evitar que os centros sejam inundados. Esse paradoxo é resolvido criando-se inscrições que conservem, simultaneamente, o mínimo e o máximo possível, através do aumento da mobilidade, da estabilidade ou da permutabilidade desses elementos. Essas "centrais de cálculo" seriam, assim, os cernes de uma extensa rede de conhecimento. Para elas, direcionar-se-ia uma infinidade de inscrições em forma de amostras, observações etc, a fim de serem debatidas e estudadas em um ambiente controlado. 
ções por exploradores ávidos por preencher os últimos espaços em branco nos mapas africanos, uma infinidade de informações é produzida. Aqui a visão dos exploradores cientistas tende a reificar os sujeitos, seja pela descrição etnográfica, seja pela busca em seus desenhos de traços diacríticos acerca das populações autóctones. As narrativas dos exploradores tendem a ser intemporais, com descrições que definem paisagens imóveis - humanas, visuais, sonoras -, suspendendo a dinâmica histórica dos inúmeros grupos populacionais, e as vicissitudes do espaço circundante, para registrar o momento em que ali estiveram.

Para focarmos dois exemplos, basta observar as cartas topográficas elaboradas por Capelo e Ivens durante a sua segunda expedição e o rigor com que traçam, muitas vezes, o curso de rios intermitentes, as mololas, e as pequenas lagoas, tornando presentes paisagens sazonalmente ausentes. ${ }^{6}$ Além disso, fixam com precisão algumas das populações do sul de Angola, que, a despeito de uma organização política centralizada, têm como traço distintivo a transumância, como é o caso dos reinos Cuamato e Cuanhama. Não obstante, uma leitura mais atenta das narrativas de viagens dos autores permite dirimir essa visão estática presente em sua cartografia. Seus próprios embaraços e limitações são indicativos de uma dinâmica dificilmente apreensível durante a efêmera passagem pelos sertões. Dessa forma, buscar-se-á confrontar as descrições desses modernos exploradores com os diários do sertanejo Silva Porto, pois assim será possível perceber a capacidade transformadora africana após uma maior integração com o comércio de longa distância, tanto na relação do povo com a natureza quanto nas relações interpessoais.

\section{No Eldorado do marfim}

Durante a segunda metade do século XIX, os comerciantes do Bié viram despontar um novo e rico mercado de marfim. A expansão da fronteira comercial para o baixo Cubango fez com que as reservas da corte do Barotze fossem incorporadas ao comércio por volta dos anos de 1840 . Pelo menos até 1860, os comerciantes sertanejos luso-africanos detinham o monopólio desse Eldorado do marfim. Seu comércio provocou inúmeras transformações em toda a África Central. No tocante às mudanças da relação com o ambiente, é notável o caso dos "casséqueres" (Khoisan). Ao cruzar com membros desse grupo, Serpa Pinto coloca-os

6 A molola é uma depressão do terreno que recebe água durante a estação chuvosa, não se constituindo, porém, em um leito de rio ou ribeiro. Segundo Capelo e Ivens (1886, p. 261), as extremidades das mololas têm distante conexão com a margem de alguns rios, notadamente o Cunene e o Cubango. Assim sendo, quando esses alcançam uma maior elevação durante o período de chuvas, eles derivam suas águas para a entrada da molola, acumulando-as após o declive do nível da corrente. 
no estágio mais primitivo e imóvel que se pode imaginar, afirmando que "são os verdadeiros selvagens da África tropical do sul, os outros povos podem ser chamados de bárbaros" (PINTO, 1881, p. 281). Coabitando com os Ambuelas no vasto território que se estende entre os rios Cubango e Cuando, ainda segundo o autor, os "casséqueres" não conheciam qualquer tipo de comércio, exceto quando a fome grassava e os obrigava a permutar marfim e cera com os vizinhos.

Fora da terra dos Ambuelas, próximo às margens do rio Caculovar, nas terras do Humbe, Capelo e Ivens tiveram uma impressão muito semelhante ao encontrarem com "casséqueres" que transitavam pela região. Os autores afirmam que eles "vivem nos recônditos dos bosques, em míseras cubatas; a sua alimentação consiste no mel e na carne; o seu maior prazer é o isolamento!" (CAPELO; IVENS, 1886, p. 207). Na descrição que se segue, mais uma vez, prevalece uma visão estática e intemporal dos Khoisan. Tanto Serpa Pinto quanto Capelo e Ivens não são capazes de compreender os efeitos do avanço da fronteira comercial sobre o modo de vida dessas populações.

A visão que se tem dos "bosquímanos" como povos primitivos e extremamente isolados também foi compartilhada por exploradores britânicos que estiveram na colônia do Cabo (PRATT, 1999). Esse isolamento observado pelos exploradores é fruto de um processo histórico de longa duração. À mercê da ocupação da colônia do Cabo, os Khoisan foram repelidos para o norte, onde encontraram com grupos Banto guerreiros. As guerras e escaramuças travadas em ambos os lados levaram parte considerável desses caçadores-coletores a se refugiarem em zonas marginais, como as terras do Khalarrari e do deserto da Namíbia, bem como entre os rios Cunene e Cubango (ESTERMANN, 1983, p. 35).

Bem diferente é a visão de Silva Porto que, por ter tido contato com os "casséqueres" ao longo de muitos anos, pôde perceber transformações provocadas pela abertura do comércio de longa distância. Segundo os diários do portuense, os integrantes dos grupos "bosquímanos" desconheciam o valor de recurso natural do marfim até a abertura do comércio de longa distância com o Barotze, em 1845. Apenas a carne do elefante era recolhida por esses exímios caçadores, enquanto as presas dos animais abatidos eram deixadas para trás. Silva Porto relata em seu diário que os encontrou "com grande provimento de carne de três elefantes e abundância de mel, que o povo da caravana comprou por missangas e tabaco, fazendo grande provisão de ambos os objetos. O chefe dessa gente nos fez presente dos dentes dos citados animais" (PORTO, 1986, p. 335).

O antropólogo Carlos Estermann (1983, p. 37), que escreve quase um século depois, observa que o isolamento desses grupos deve ser relativizado, por exemplo, pelo uso de utensílios domésticos de fabricação Banto. Além disso, a escolha do sítio em que eles levantavam acampamento levava em conta a proximidade com outros povos: "acontece que, grupos que não distam muito das habitações 
dos negros, preferem ir instalar os seus acampamentos ao lado dessas habitações para dois ou três meses de cada ano". É o período em que a floresta diminui seu potencial em caça e coleta, mas que coincide com a colheita das plantações de milho e massango dos povos Banto. As mulheres "bosquímanas" participam da colheita em troca da ração diária. É bem provável que esse tipo de relação interétnica já fosse prática corriqueira no período em que os exploradores portugueses cruzaram com os "casséqueres", pois é notável que os seus acampamentos estivessem no meio "de aldeias e campos cultivados" (CAPELO; IVENS, 1886, p. 208).

O afã dos sertanejos por peles, penas de avestruz e, sobretudo, marfim pode ter modificado a relação que esses habitantes tinham com a atividade cinegética. É também possível que o aparecimento de rotas concorrentes de bôeres vindas do Khalarrari a partir da década de 1860 (PORTO, 1986, p. 117-132) tenha impulsionado uma mudança nesse sentido.

No caso português, vale ressaltar que a busca por tal recurso natural foi profundamente impactada pelo fim do monopólio régio em 1834. Os preços que até então eram mantidos virtualmente baixos nos principais portos de Angola passaram a subir exponencialmente, bem como o seu volume de exportação (DIAS; ALEXANDRE, 1998, p. 382). Para que se tenha uma ideia, as exportações de marfim a partir de Luanda subiram de 3.000 libras em 1832 para 105.000 libras em 1844, apenas dez anos após a queda do monopólio (DELGADO, 1940, p. 111-112).

Ainda segundo as narrativas de Silva Porto, pode-se depreender que outros grupos foram muito hábeis em negociar e se adaptar aos lucros advindos do comércio do marfim. Os caçadores Quioco reconheceram muito cedo o valor que passou a ser atribuído às presas de elefante pelos sertanejos, bem como pelo Muatianvua, ao qual eram devedores de tributos. Em seu opúsculo, Silva Porto afirmou que a guerra perpetrada pelos Quioco ao paquiderme levou à fuga em massa das manadas, pelo que os caçadores passaram a ultrapassar seus territórios ancestrais. A caça em terras alheias carecia de novos arranjos, "ficando o caçador com o dente esquerdo e dando o direito ao senhorio em cujo domínio era morto o elefante" (PORTO, 1891, p. 44). Segundo Juliana Ribeiro da Silva (2008, p. 131), a partir de 1850, esse povo começou a subir para o norte, seguindo as manadas até a margem direita do rio Kwango (Cuango). Não é absurdo imaginar, no entanto, que nem sempre esse acordo tenha sido respeitado, gerando graves conflitos. Além disso, a caça do elefante favoreceu a concentração bélica dos Quico (Cokwe), proporcionando-os os meios de abalar as autoridades políticas do Muatianvua (DIAS, 2003, p. 35). 


\section{No universo pastoril}

Não obstante, nem todas as manadas se embrenharam na floresta tropical. Parte delas deve ter migrado rumo ao ocidente, refugiando-se nas terras de domínio dos Humbe, como é possível inferir a partir da descrição de Capelo e Ivens. Ao transitarem pelas terras do sul de Angola em 1885, os viajantes descreveram o território Humbe como uma verdadeira arca de Noé, cuja profusão da fauna bravia já começava a atrair célebres caçadores, como Axel Wilhelm Eriksson. Além disso, também eram atraídos os bôeres, que há pouco tinham se estabelecido em Humpata, no planalto de Huíla. ${ }^{7}$ Segundo os autores, a razão para a existência dessa reserva de caça "tão próximo da residência do homem, consiste em dois fatos especiais: a natureza das florestas, exclusivamente compostas em grandes zonas do espinheiro, o que as torna impenetráveis, e a abundância dos gados, fazendo com que o indígena pouco ou nada pense em caçar" (CAPELO; IVENS, 1886, p. 209). Impressão semelhante tivera o sertanejo Brochado quarenta anos antes. Ao que parece, coube a esse comerciante e a seus encarregados a integração dessa porção meridional da Angola hodierna ao comércio de longa distância, durante a década de 1840 (PORTO, 1986, p. 372). Como um comerciante do sertão, Brochado possuía especial interesse na produção de marfim, pelo que afirma: "há ali grande abundancia de elefantes, de maneira que se tal gente fosse dada à vida de caçador, aquelas terras se tornariam de mais comércio de marfim; porém é vida pela qual não trocam a de pastor" (BROCHADO, 1867, p. 189).

A predileção desses pastores pelo gado bovino parece ter facilitado a coabitação entre as espécies selvagens e a animália doméstica, desde que aquelas não ameaçassem a pastorícia. Grandes predadores e animais peçonhentos podem ter sido vistos com menos desdém por parte dos Humbe. A atenção era redobrada no período de estiagens, pois os pontos de aguadas e as margens dos rios Caculovar e Cunene eram simultaneamente visitados pelos rebanhos e pela fauna bravia sedenta. Nesse período, os Humbe preparavam armadilhas terrestres em forma de grandes fossos cobertos com madeira e capim, a que chamavam de mahinas (BROCHADO, 1867, p. 189). Porém, em termos de perda do cabedal, quer por mortes, quer por competição ecológica, esses animais selvagens não constituíam a maior preocupação.

É revelador, nesse sentido, a impressão tida pelo sertanejo Brochado, que percebeu a disputa por gado entre os Humbe, aquém-Cunene, e os Kwanhama

7 Desde agosto de 1878 um trek bôer negociava com o cônsul-geral de Portugal no Cabo a possibilidade de se instalar no planalto da Huíla, o que veio a conseguir dois anos depois, após o enfrentamento direto com o soba do Humbe (PÉLISSIER, 2013, p. 144-148). 
(Cuanhama), além-Cunene. ${ }^{8} \mathrm{O}$ autor afirmou que as razias e as disputas de gado se davam geralmente nos meses mais secos, entre julho e dezembro, pois o baixar das águas do rio Cunene possibilitava a travessia a pé em determinados trechos, sendo esse o momento mais oportuno para as incursões dos Kwanhama (BROCHADO, 1867, p. 188). A competição por rebanhos entre os dois grupos foi algo constante até meados do século XX e serviu como uma das principais justificativas para a efetiva ocupação do território por parte do governo português entre 1890 e 1914 (PELLISSIER, 2013). Outro fator de grande morticínio do gado, e que atingia não somente os Humbe, mas todos os grupos do universo pastoril do planalto sul de Angola, foi a propagação de uma doença infectocontagiosa cognominada caonha. A disseminação dessa peri-pneumonia pela África austral foi atribuída por Capelo e Ivens (1886, p. 235) ao viajante explorador James Chapman, que teria levado um gado contaminado durante sua primeira viagem ao lago N'gami, em 1854. De fato, Chapman menciona em seu relato o pavor gerado entre os Nama e os territórios circunvizinhos pela grande mortandade decorrente da pneumonia do gado recém infectado (CHAPMAN, p. 433-434). A doença se espalhou com muita rapidez, atingindo a reserva de gado Humbe pela primeira vez em 1861 (BSGL, 1877, p. 80).

Pequenos booms comerciais acompanharam a disseminação da epizootia do gado. Durante os surtos epidêmicos, os Humbe procuravam com maior interesse os comerciantes luso-africanos, no intuito de mitigar o desastre com a venda das peles do gado adoecido. A exportação das peles de gado serviu de marcador da chegada da peste e do impacto que ela exerceu sobre a economia Humbe. Segundo Alfredo de Albuquerque Felner (1940, p. 57), a exportação de couro pelo porto de Moçâmedes nos anos de 1858, 59, 60 e 61 foi, respectivamente, de $1.909 \$ 538,1.970 \$ 523,2.937 \$ 692$ e $5.060 \$ 980$. Em 1862 esse número saltaria para $44.372 \$ 960$.

Novos surtos ocorreriam ao longo dos anos, de modo a reduzir significativamente os rebanhos de bovinos. Além disso, a vacinação do gado foi o ponto fulcral dos conflitos luso-Humbe desencadeados em 1898.

8 As designações aquém e além Cunene aparece na documentação coeva para distinguir o médio curso do rio, sendo aquém a margem direita - portanto o oeste, e além a margem esquerda - o leste. 


\section{Considerações finais}

A incorporação do planalto sul de Angola pelas caravanas de longa distância, a partir da segunda metade do século XIX, transformou profundamente as relações de poder, a paisagem, as formas de integração entre os diversos grupos, dentre outras questões. A breve leitura proposta neste capítulo indicou o protagonismo africano nessas mudanças, não percebendo suas ações apenas como uma resposta automática ao estímulo europeu. Os casos da ressignificação cultural sobre o marfim e da modificação da paisagem em decorrência da caça ao elefante foram aqui apresentados como exemplos da capacidade transformadora dos grupos da porção meridional de Angola.

A leitura das narrativas de sertanejos e exploradores indicou-nos que diferentes grupos fizeram escolhas diversas frente à demanda comercial dos centros de Angola. Com a chegada dos comerciantes, importantes agentes sociais, como os Quioco, foram muito hábeis em negociar e atender às demandas dos sertanejos, de modo que em um curto prazo de tempo eles acumularam armas de fogo modernas e puderam desequilibrar antigas relações de força que mantinham com o império da Lunda.

Enquanto isso, os Humbe, principal grupo do universo pastoril, não se transmutaram em exímios caçadores, nem abandonaram a pastorícia apenas para suprir o desejo dos negociantes do mato. Por isso, Elisete da Silva (2003, p. 15) afirma que mesmo durante o período colonial "a comercialização plenamente voluntária de gado nunca correspondeu à maciça procura europeia”. Os Humbe e outros grupos do universo agropastoril permaneceram negociando os couros e parte do gado que possuíam sem aderir integralmente à lógica de mercado, buscando um difícil equilíbrio entre suas necessidades por bens de consumo e de uso e a demanda por gado das zonas centrais, notadamente Moçâmedes e Benguela.

\section{Referências}

ALEXANDRE, V. O império português (1825-1890): ideologia e economia. Análise Social, Lisboa, v. XXXVIII, p. 959-979, 2004.

BORY, P. Les explorateurs de l'Afrique. Tours: Alfred Mame et Fils, 1890.

BRUNSCHWIG, H. A partilha da África negra. 2. ed. São Paulo: Perspectiva, 2013.

DIAS, J. Caçadores, artesãos, comerciantes, guerreiros: os Cokwe em perspectiva histórica. In: HEUSCH, Luc de; DIAS, Jill. A antropologia dos Tshokwe e povos aparentados. Porto: FLUP, 2003. p. 17-47.

DELGADO, R. A famosa e histórica Benguela: catálogo dos governadores (1779-1940). Lisboa: Edições Cosmos, 1940. 
ESTERMANN, C. Etnografia de Angola (sudoeste e centro): coletânea de artigos dispersos. Lisboa: Instituto de Investigação Científica e Tropical, 1983.

FELNER, A. de A. Angola: apontamentos sobre a colonização dos planaltos e litoral do sul de Angola. Lisboa: Agência Geral das Colônias, 1940.

FREUDENTHAL, A. Voz de Angola em tempo de ultimato. Estudos Afro-Asiáticos, Rio de Janeiro, ano 23, n. 1, p. 135-169, 2001.

GUIMARÃES, A. Uma corrente do colonialismo português: a sociedade de geografia de Lisboa (1875-1895). Lisboa: Livros Horizonte, 1984.

LATOUR, B. Ciência em Ação: como seguir cientistas e engenheiros sociedade afora.

Tradução de Ivone Benedette. São Paulo: Unesp, 2010.

MÚRIAS, M. Travessia da África. Lisboa: Agência Geral das Colónias, 1936.

PÉLISSIER, R. História das campanhas de Angola. Lisboa: Editora Estampa, 2013. v. 2.

PRATT, M. L. Os olhos do império: relatos de viagem e transculturação. Bauru: EDUSC, 1999.

SANTOS, M. E. M. O estudo da hidrografia numa região de civilizações de terra, a África Austral. Coimbra: Coimbra Editora, 1985.

- Viagens de exploração terrestre dos portugueses em África. Lisboa: Centro de Estudos de Cartografia Antiga, 1978.

. Perspectiva do comércio sertanejo do Bié na segunda metade do século XIX.

Lisboa: Junta de Investigações Científicas do Ultramar, 1981.

. Em busca dos sítios do poder na África centro-ocidental: homens e caminhos, exércitos e estradas (1843-1915). In: HEINTZE, Beatrix (Org.). Angola em movimento: vias de transporte, comunicação e história. Frankfurt: Lembeck, 2008. p. 32-37.

SILVA, E. M. da. Impactos da ocupação colonial nas sociedades rurais do sul de Angola. Lisboa: CEA, 2003.

SILVA, J. R. da. Homens de ferro: Os ferreiros na África Central no século XIX. 2008. 157 f. Dissertação (Mestrado) - Curso de História Social, Universidade de São Paulo, São Paulo, 2008.

STANLEY, H. M. Através do continente africano. Mem Martins: Gráfica Europam, 2007.

WESSELING, H. Dividir para dominar: a partilha da África (188-1914). Rio de Janeiro: Editora UFRJ: Editora Revan, 1998.

WESSELING, H. Les empires coloniaux européens (1815-1919). Paris: Gallimard, 2009. 


\section{Fontes}

BSGL - Boletim da Sociedade de Geografia de Lisboa. Porto: Typographia de Freitas Fortuna, 1877.

BSGL - Boletim da Sociedade de Geografia de Lisboa. n. 3. Porto: Typographia de Freitas Fortuna, 1878.

BRAZZA, P. S. de. Au cour de l'Afrique: vers la source des grands fleuves (1875-1877). Paris: Phébus, 1992.

BROCHADO, B. J. Descripção das terras do Humbe, Camba, Mulondo, Quanhama, e outras [...] - 1850. In: Annaes do Conselho Ultramarino: parte não oficial. Lisboa, 1867.

CAPELO, H.; IVENS, R. De Angola à contracosta: descrição de uma viagem pelo continente africano. Lisboa: Imprensa Nacional, 1886.

. De Benguella às terras de Iácca: descrição de uma viagem na África Central e Ocidental. Lisboa: Imprensa Nacional, 1881.

CHAPMAN, J. Travels in the interior of South Africa. Londres: Willian Clowes Ltd., 1868.

LIVINGSTONE, D. Livingstone's travels and researches in South Africa: including a sketch of sixteen years' residence in the interior of Africa, and a journey from the Cape of Good Hope to Loanda on the west coast, thence across the continent, down the river Zambesi to the eastern ocean. Filadélfia: G. G. Evans, 1859.

. Narrative of an expedition to the Zambesi and its tributaries; and of the discovery of the lakes Shirwa and Nyassa (1858-1864). Londres: John Murray, 1865.

PINTO, A. de S. Como eu atravessei a África do Atlântico ao mar Índico, viagem de Benguella à contra-costa, através de regiões desconhecidas; determinações geographicas e estudos ethnographicos. Londres: Sampson Low, Marston, Searle e Rivington Editores, 1881. v. 2.

PORTO, A. F. F. da S. Viagens e apontamentos de um portuense em África: diário de António Francisco Ferreira da Silva Porto. Coimbra: Biblioteca Geral da Universidade de Coimbra, 1986.

. Silva Porto e Livingstone. Lisboa: Typographia da Academia Real das Sciencias, 1891. 